\title{
EDITORIAL
}

\section{COVID-19 is a trigger for transformation in pharmacy education for West Africa}

\author{
Mahama Duwiejua \\ School of Pharmacy, College of Health Sciences, University of Ghana, Accra, Ghana
}

\author{
Correspondence \\ Mahama Duwiejua \\ School of Pharmacy \\ $\mathrm{CHS}$ \\ University of Ghana \\ Legon \\ Accra \\ Ghana \\ mduwiejua54@gmail.com
}

\begin{abstract}
The novel coronavirus 2019 (COVID-19) pandemic has irreversible disrupted key services including education. Terms like the 'new normal' reflect the lost hope of returning to pre-COVID times. This editorial describes the challenges and responses of educators and governments in West Africa to COVID-19. To avert further harm posed to pharmacy education and practice, the publication advocates for innovation. Pharmacy leaders in West Africa are challenged to look at the other side of the coin, avoid inefficient panic-driven solutions and seek opportunities for change in the challenges. The paper provides a direction for change and specifically identifies collaboration with partners within the region and beyond including quality continuous professional development programmes for leadership development, re-training of educators and practitioner development.
\end{abstract}

The novel coronavirus disease 2019 (COVID-19) has sharpened our awareness of the reality of globalisation and how interconnected our world is. This pandemic makes the first stanza of Bob Dylan's 'The Times They Are A-Changin' resonate more with the following words:

Come gather'round people

Wherever you roam

And admit that the waters

Around you have grown

And accept it that soon

You'll be drenched to the bone

If your time to you is worth savin'

Then you better start swimmin'

Or you'll sink like a stone

For the times they are a-changin'
The environment is unstable and the future is unpredictable. What is certain is that COVID-19 has exacerbated the overall global disease burden. Consequently, many panic-driven responses have emerged from institutions to avoid 'sinking like a stone'. The zeitgeist everywhere is 'change'. However, change per se is not the answer; it must be backed by evidence of need. Adaptability in the sense of the Darwinian theory of evolution is what will guarantee the resilience and survival of pharmacy, now and in the foreseeable future. This is the spirit behind the International Pharmaceutical Federation (FIP)'s statement that 'the future workforce needs to be flexible in its development, adaptable to change, and consciously competent within known scopes of practice' (FIP, 2016). Whether this statement is viewed as rhetoric or reality remains to be determined by subsequent events. Ghana recorded its first two cases of COVID-19 in March 2020. By August, the country had recorded over 44,000 cases with 276 deaths. The Government response to the pandemic has largely focused on containment of spread of the virus. Measures 
taken included a partial lockdown of the country and closure of schools, including universities, resulting in interruption of the academic year. Experiential training and pre-registration internships have been suspended to protect students from exposure to the virus. Additionally, government's insurance packages for health workers do not cover students and interns.

To save the academic year, all lectures and examination of students were carried out via online platforms. Brick-and-mortar structures now have diminished in importance, as virtual classrooms have replaced face-to-face interactions between faculty and students in a physical space.

With no experience in this 'new way' of doing things, schools did things their way. However, there is concern about the impact of these 'new' tools on the quality of teaching, learning, and assessment for a professional programme like Pharmacy. For instance, internet accessibility is unevenly distributed in the country, making it impossible for some students to have uninterrupted participation in lectures and assessments. Moreover, the cost of internet services is a disincentive for both faculty and students exploring new and more efficient ways of teaching and learning. The integrity of examinations is equally questionable. Indeed, results of the end of semester examinations vindicates this suspicion, as a clear difference has emerged between students' performance now and pre-COVID-19, with the former being significantly higher.

Institutional and external quality assurance mechanisms have not kept pace with the 'new normal'. Online teaching cannot replace the role of lecturers as mentors and role models, just as remote contact with students cannot adequately address the problems of students with special needs.

Furthermore, the impact of these disruptions on laboratory-based courses are yet to be assessed. There is suddenly a plethora of online continuing education programmes organised by a diversity of resource persons. While these may be useful in some cases, others may be of dubious quality and relevance, targeting an already overburdened audience. What is the regulator's response?

Yes, there can be no competent workforce without quality education. The future now is not a distant concept. It is here because of COVID-19. So the flexibility and adaptability of the pharmacy workforce in Ghana and West Africa will be measured by our response to the pandemic. A rapid assessment of the impact, real and potential, of the pandemic on institutions of training, students, and related structures should form the basis for any response.

Out of adversity comes opportunity. Education providers in the region need to be more creative, exhibit more ability to harness resources, and build teams that work collaboratively. The West African Postgraduate College of Pharmacists has demonstrated how technology can be used to harness human resource capacity in the region for training, as lectures are being delivered by resource persons from different countries to students of the college in different countries.

Suddenly, the feasibility of the FIP-UNESCO UNITWIN project for establishing the Africa Virtual Centre of Excellence is obvious. The concept is no longer an abstraction.

Closure of the country's borders, coupled with measures taken by China and India to protect pharmaceutical supplies for their countries, have exposed the vulnerability of the pharmaceutical sector and the danger of overdependence on external sources. The disruption to the pharmaceutical supply chain has resulted in shortages of essential medicines and critical medical supplies. Under the current circumstances, the government has acknowledged the value of pharmaceutical services by calling on the pharmaceutical industry to improve the situation. Industries and schools of pharmacy have responded by producing sanitizers and other related supplies. A state in Nigeria has commissioned a committee to look for a cure for the infection. It is significant that the team is led by a pharmacist.

Under these circumstances of scarcity, the risk of fake and substandard drugs being prevalent is high. Is anyone ensuring the monitoring of the quality of these items in these desperate times? How can the profession use these opportunities to advocate for society's support for change in advancing pharmacy practice?

COVID-19 is testing pharmacy's capacity to 'accept responsibility and accountability for improving global health and patient health outcomes by closing gaps in the development, distribution, and responsible use of medicines', as stated in the centennial declaration of FIP (FIP, 2012).

The gaps in 'development, distribution, and responsible use of medicines' as determined earlier by the profession have widened (FIP, 2012). The long-standing resource constraints of the country/region have been exacerbated by COVID-19-induced shrinking of the economy. 


\section{What is the way forward?}

Quality leadership in times of crisis is critical. The desired outcome can only be achieved with a vibrant, visionary, and focused leadership. Stale leadership styles will sink the profession and fail society. Fortunately, the FIP Deans' Forum offers excellent mentoring opportunities for developing academic leaders. Deans and pharmacy leaders in Ghana and West Africa are encouraged to take advantage of the opportunities provided. An excellent example is the Global Academic Leadership Fellows Programme, a product of the collaboration between FIP and the American Association of Colleges of Pharmacy. The current course 'Enhancing Academic Leadership Horizons in Trying Times' promises to be useful.

The response of schools of pharmacy to the pandemic goes beyond a stock-taking exercise. A deeper reflection of the current training is required, as more is expected in the face of shrinking resources. The framework for change is provided for in the Nanjing Statements on Pharmacy and Pharmaceutical Sciences Education and the FIP Pharmaceutical Workforce Development Goals (PWDGs). The FIP, through a rigorous process of consultation and validation, developed these documents to guide education providers, schools of pharmacy, and providers of continuing professional development and continuing education programmes. The Nanjing Statements are important tools for self-assessment and identification of gaps.

The PWDGs form milestones for providing needs-based education for countries as the guidelines on academic capacity, foundation training, quality assurance, working with others in the health care team, and continuing professional development strategies are useful targets for schools desiring change. Lack of respect for these guidelines present a real danger of leadership failure, loss of focus, and production of half-baked and dangerous graduates parading as professionals and experts.

Ghana and the region must not go this way. In spite of COVID-19, the region must continue to show resilience and commitment to FIP's ideal of:

'Producing high quality professionals for high quality patient care, public health, and scientific advancement objectives" and "ensuring all education and training delivered to our professional workforce is of the highest quality and prepares them well for current and future roles'. (FIP, 2016).

It is time to engage policy makers, patients, and civil society groups to support the advancement of pharmacy practice through a curriculum reform. There still exists a visible gap in the knowledge and practices of the general population regarding COVID-19. Changes in curriculum should include competencies in health promotion targeted at community pharmacy practice. Pharmacybased vaccination programmes should be promoted, through both pre-service training and continuing professional development programmes, as a vital resource for mass vaccination coverage of the population.

Can the pharmacy leadership in Ghana and West Africa look beyond COVID-19 disruptions and see the promise of a transformed professional education and practice?

\section{References}

FIP [International Pharmaceutical Federation]. (2012). Centennial declaration: Improving global health by closing gaps in the development, distribution and responsible use. Available at: https://www.fip.org/files/fip/news/CentennialDeclaration 20-final version.pdf

FIP [International Pharmaceutical Federation]. (2016). Global Vision for Education and workforce. 2016 Presented at the global conference on pharmacy and pharmaceutical sciences education, Nanjing, China. Available at: https://www.fip.org/files/content/ pharmacy-education/fip-education/global-vision-for-education.pdf 